
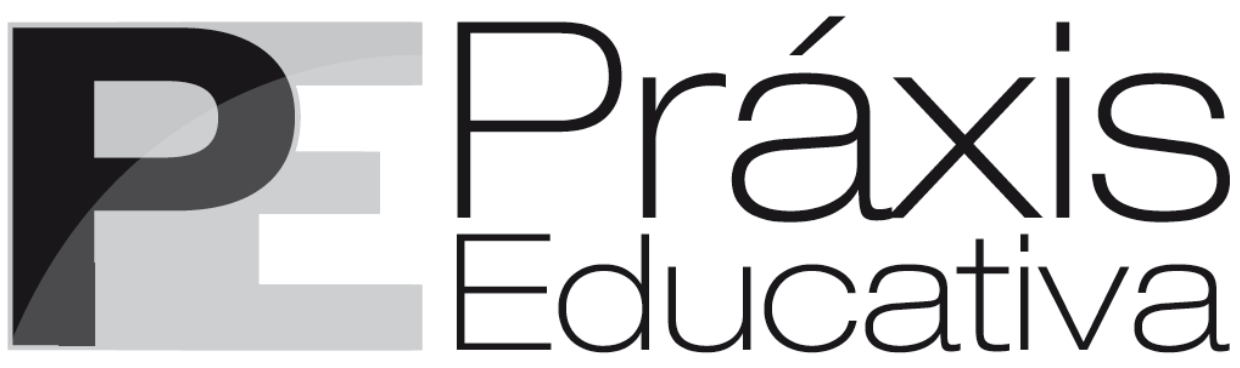

ISSN 1809-4031

elSSN 1809-4309

https://doi.org/10.5212/PraxEduc.v.16.16594.021

\title{
Pensamento/ação freiriano: pistas para uma epistemologia descolonial que cimente uma Ecologia Humana contra-hegemônica
}

\section{Freirean thinking/action: clues to a decolonial epistemology that cements a counter-hegemonic Human Ecology}

\section{Pensamiento/acción freiriano: pistas para una epistemología descolonial que cemente una Ecología Humana contrahegemónica}

\author{
Maria Elizabeth Souza Gonçalves* \\ iD https:/ / orcid.org/0000-0003-3487-5334 \\ Luciano Sergio Ventin Bomfim** \\ (iD) https://orcid.org/0000-0002-7161-3002
}

Resumo: Este estudo teve como objetivo analisar as contribuições do pensamento/ação freiriano na construção de uma epistemologia descolonial, orientadora de uma Ecologia Humana latino-americana de viés contra-hegemônico. Por meio de uma revisão de literatura da produção freiriana e de intelectuais da Ecologia Humana latino-americana, fez-se uma interlocução de saberes e perspectivas, o que permitiu anunciar Paulo Freire como um clássico na genealogia do pensamento descolonial e no fortalecimento de uma Ecologia Humana comprometida com justiça social, cognitiva e ambiental, acenando processos emancipatórios advindos de diferentes frentes de luta, em tão especial tempo histórico de ascensão de opressões articuladas pelo capitalismo com o patriarcado e o colonialismo.

Palavras-chave: Pensamento/ação freiriano. Epistemologias descoloniais. Ecologia Humana.

Abstract: This study aimed to analyze the contributions of the Freirean thinking/action in the construction of a decolonial epistemology that orients a Latin-American Human Ecology of counter-hegemonic inclination. Through a literature review of the Freirean production and the Latin-American intellectuals of the Human Ecology, it was done the interlocution of knowledge and perspectives, resulting to announce Paulo Freire as a classic in the genealogy of decolonial thinking and in the reinforcing of a Human Ecology engaged with social, cognitive and environmental justice, signaling emancipatory processes coming from different fronts of struggle, in such a special historical time of rise of oppressions articulated by capitalism with patriarchy and colonialism.

Keywords: Freirean thinking/action. Decolonial epistemologies. Human Ecology.

\footnotetext{
* Professora da Universidade do Estado da Bahia (UNEB). Mestre em Educação e Mestre em Ecologia Humana. Doutoranda em Ecologia Humana. E-mail: <lizbethgoncalves@hotmail.com>.

** Professor da Universidade do Estado da Bahia (UNEB). Mestre em Educação. Doutor em Filosofia. E-mail: $<$ lsvbomfim@gmail.com>.
} 
Resumen: Este estudio tuvo como objetivo analizar las contribuciones del pensamiento/acción freiriano en la construcción de una epistemología descolonial orientadora de una Ecología Humana latinoamericana con un sesgo contrahegemónico. Por medio de una revisión de la literatura de la producción de Freire y de los intelectuales de la Ecología Humana latinoamericana, se hizo una interlocución de saberes y perspectivas, lo que permitió anunciar a Paulo Freire como un clásico en la genealogía del pensamiento descolonial y en el fortalecimiento de una Ecología Humana comprometida con justicia social, cognitiva y ambiental, señalando procesos emancipatorios surgidos de diferentes frentes de lucha, en tan especial tiempo histórico de ascenso de opresiones articuladas por el capitalismo con el patriarcado y el colonialismo.

Palabras clave: Pensamiento/acción freiriana. Epistemologías descoloniales. Ecologia Humana.

\section{Introdução}

A década de 1960, em chão brasileiro, embrionava um pensamento-ação, inicialmente batizado de Método ${ }^{1}$ Paulo Freire. Para além de um Método de alfabetização, Paulo Freire apresentou, como fruto de suas experiências educativas, um pensamento libertador à luz de um momento histórico peculiar e, ainda, como resposta às demandas societais próprias desse tempo e do lugar de onde pensava/agia.

Consciente de que a educação não era a salvadora da crise social e econômica que seu país vivenciava, mas seguro de que a democratização da sociedade não prescindia da democratização da cultura, Freire (1967) sistematizou, em comunhão com outros educadores, pesquisadores e artistas, um método de alfabetização de adultos que permitisse aos povos marginalizados dos campos e das cidades assumirem sua condição de sujeitos, construtores de seus mundos.

O educador nordestino orientava dois princípios basilares a seu método: a politicidade do ato educativo aliada à concepção de que essa educação só se daria caso nascesse do diálogo, do encontro de homens e mulheres livres. Iniciava-se, pois, um período de transição paradigmática do processo educativo e de um modo de pensamento engajado, corporificado a partir da prática, com vistas à consciência do ser humano de estar no mundo, e que repercutiria em outras áreas do conhecimento humano. Embora brotasse em um chão específico, ressoaria em outros terrenos similares (FREIRE, 1967, 2005).

No eixo estruturador do pensamento de Paulo Freire (1967), encontra-se a ideia de que os processos emancipatórios se dão na comunhão de seres humanos incompletos e inconclusos, e que a educação dos oprimidos consubstancia um projeto de sociedade emancipador que rompe com a colonialidade (SANTOS, 2010; MENEZES, 2016; LUGONES, 2014; MIGNOLO, 2003, 2010) forjadora de opressões.

O estabelecimento do encontro dos ideais freirianos com as perspectivas descoloniais está ocorrendo, sobretudo, em um período em que a ascensão do fascismo social (SANTOS, 2010) vem ganhando força no Brasil. Penna (2014), ao enfatizar pontos de diálogo da Pedagogia do oprimido (FREIRE, 2005) com as epistemologias descoloniais, propõe-se a pontuar o caráter pedagógico dessas perspectivas nas Ciências Sociais, especialmente pela ruptura com o protagonismo discursivo eurocêntrico que a descolonialidade propõe. Dentre as dimensões apresentadas, o estudo destaca elementos para consolidar o lugar na produção dos saberes que a América Latina tem assumido, tanto pela contribuição do pensamento de Freire na compreensão das estruturas

\footnotetext{
${ }^{1}$ No livro Educação como prática de liberdade (FREIRE, 1967), a palavra "Método" aparece para delinear as cinco fases do processo de alfabetização/conscientização, cujos princípios são a dialogicidade e a politicidade. Em Pedagogia do oprimido (FREIRE, 2005), a palavra "Método" é deslocada para o termo "Metodologia", concernindo o processo de codificação e descodificação das situações existenciais, cimentando a pedagogia do oprimido e a pedagogia libertadora que se propõe nesse ensaio.
} 
opressoras como nas reflexões oportunizadas pelas perspectivas descoloniais na constituição de pensamentos e práticas emancipatórias.

A dimensão pedagógica do pensamento descolonial nas Ciências Sociais da América Latina, o lugar de enfrentamento ao eurocentrismo que a educação popular assume e, especialmente, a interrelação do pensamento/ação libertador/a de Paulo Freire com as perspectivas emancipatórias têm possibilitado o vínculo do ideal freiriano de educação como prática de liberdade às epistemologias descoloniais (BARBOSA, 2016). Assim, o cruzamento do pensamento freiriano com a base nuclear das epistemologias descoloniais tem dado ao educador brasileiro um protagonismo na principiologia da pedagogia descolonial latino-americana (MOTA NETO, 2017), ainda que, no estudo mencionado, o colombiano Orlando Fals Borba também apareça com similar contribuição.

Contudo, em que medida a práxis freiriana extrapola a teoria da educação e cimenta uma epistemologia, um modo de orientar a produção do conhecimento nas diversas áreas do conhecimento humano que desestabiliza a colonialidade? Quais as contribuições do pensamento/ação freiriano na consolidação da Ecologia Humana, campo de conhecimento não disciplinar que estuda as relações dos seres humanos com seu entorno, em um rompimento com a colonialidade do ser, do saber e do poder? Nesse sentido, este estudo teve como objetivo analisar as contribuições do pensamento/ação freiriano na construção de uma epistemologia descolonial orientadora de uma Ecologia Humana latino-americana de viés contra-hegemônico. Utilizando-se de uma revisão de literatura sobre a produção freiriana, especialmente seus livros Educaşão como prática de liberdade e Pedagogia do oprimido, e a produção em Ecologia Humana de Juracy Marques (2012, 2014, 2015, 2016), de Ronaldo Alvim (2012), de Iva Pires e João Craveiro (2011) e de Alfredo Wagner Almeida (2014), buscou-se estabelecer uma interlocução geradora: de um lado, o reconhecimento de Paulo Freire na genealogia do pensamento descolonial; e do outro, a consequente contribuição da práxis freiriana na construção de uma Ecologia Humana descolonial, que se estabelece em uma ecologia de saberes, no diálogo permanente da ciência com outros saberes, dentre eles a arte e a ancestralidade.

\section{Da historiografia de uma teoria da educação a uma perspectiva descolonial: muito além de um método, um modo de pensar}

Como opção metodológica da revisão da literatura freiriana, enfatizou-se, intencionalmente, em uma perspectiva historiográfica, o pensamento possibilitado por sua obra Educação como prática de liberdade (FREIRE, 1967), dialogando-se com Pedagogia do oprimido (FREIRE, 2005), grande eixo desvelador de sua filosofia e de seu fazer libertadores, com vistas a situar a epistemologia freiriana no cerne embrionário dos movimentos epistemológicos do "Sul". $\mathrm{Na}$ sequência, elucida-se a Ecologia Humana, área de conhecimento transdisciplinar (MORAES, 2008, 2010), que se desdobra de questões não resolvidas isoladamente pelas ciências sociais e naturais (PIRES; CRAVEIRO, 2011), e seu potencial descolonizador, sobretudo a partir do grupo latinoamericano que se firma trazendo para o debate uma abordagem transdisciplinar, a favor de novos jeitos descolonizantes de anunciar uma ciência comprometida tanto com sujeitos coletivos historicamente invisibilizados (ALMEIDA, 2014; BONFIM, 2017) quanto com a compreensão de que as subjetividades e as intersubjetividades são coautoras de mundos simbólicos (MARQUES, 2012, 2016).

Faz-se necessário destacar que, embora Iva Pires e João Craveiro não sejam latinoamericanos, ela e ele integram o pensamento que ora se delineia como contra-hegemônico; desse modo, o termo latino-americano aqui assumido não é uma categoria monolítica que se restringe a um espaço; funda-se em uma geopolítica que consubstancia a tripla descolonialidade: do ser, do 
saber e do poder (MIGNOLO, 2003; QUIJANO, 2010). Nesse empreendimento acadêmico, apresentam-se as conexões e as complementariedades entre o pensamento libertador de Paulo Freire e as Epistemologias do Sul e destes com a Ecologia Humana que vem se firmando em um viés contra-hegemônico. Nessa perspectiva, o texto é construído estabelecendo-se essa interlocução.

Assim, assumindo que a história e a geografia tanto podem colonizar como descolonizar, a partir de uma geopolítica comprometida com o lugar, o tempo e os seres (MOLDONADOTORRES, 2010), faz-se necessário reconhecer o espaço-tempo-seres situados e datados, a partir dos quais nascem os ideais de libertação, aqui denominado "pensamento/ação freiriano".

No Brasil, o cenário sócio-político-econômico do nascedouro do pensamento freiriano era de transição: Pernambuco, início da década de 1960, crescimento do parque industrial, investimento na indústria automobilística, surgimento da burguesia industrial (sem, no entanto, suprimir o poderio do latifúndio) ao lado da forte presença do capital estrangeiro, ascensão da indústria automobilística, construção da capital federal brasileira, inchaço das cidades fruto do êxodo rural, firmação da publicidade como orientadora de padrões de vida (FREIRE, 1967).

$\mathrm{Na}$ esfera intelectual e artística, um novo grupo com aspirações nacionais se firmava, rompendo uma tradição que enxergava o Brasil com olhos alheios. Essa geração fortemente empenhada em superar o subdesenvolvimentismo consolida um movimento de libertação nacional que dialogará e fortalecer-se-á com outros grupos de sociedades coloniais tão característicos da América Latina (MOTA, 1994).

Dá-se início a uma transição que se estabelecia sobre os quase 20 milhões de analfabetos concentrados maciçamente no campo. Quatro milhões de crianças em idade escolar fora da escola e 16 milhões de analfabetos a partir dos 15 anos (FREIRE, 1967). O problema que ganhava centralidade no pensamento engajado de Freire não era meramente alfabetizar, mas situar homens e mulheres no mundo como construtores desse mundo, enquanto se apropriavam da leitura e da escrita. Esse era o novo problema que nortearia as futuras direções de olhares.

O que Paulo Freire propunha estava muito além de um método de alfabetização, tratavase de uma forma de orientar os processos educativos visando a emancipação de um coletivo de oprimidos/as situados/as no nordeste brasileiro; um jeito novo de produzir conhecimento a partir do encontro dialógico dos saberes formais - nas mãos dos animadores/alfabetizadores -, com os saberes informais - dos/as alfabetizandos/as, buscando libertação, na certeza de que não há saber nem ignorância absolutos (FREIRE, 1967). Essa comunhão, esse diálogo de saberes e o sentimento de incompletude orientam a ecologia de saberes, caminho para a superação das injustiças sociais e cognitivas proposta pelas Epistemologias do Sul (SANTOS; MENESES, 2010).

Freire (2005) faz um convite a entender o enfrentamento à colonialidade, por ele denominado de "sistema opressor", por meio do encontro engajado de seres humanos que aprendem em comunhão, a partir do entendimento pelos/as oprimidos/as, de que a desumanização a que foram sucumbidos/as é decorrente de um saber opressor que neles/as habita. Dessa forma:

Somente quando os oprimidos descobrem, nitidamente, o opressor, e se engajam na luta organizada por sua libertação, começam a crer em si mesmos, superando, assim, sua 'convivência', com o regime opressor. Se esta descoberta não pode ser feita em nível puramente intelectual, mas da ação, o que nos parece fundamental é que esta não se cinja a mero ativismo, mas esteja associada a sério empenho de reflexão, para que seja práxis. (FREIRE, 2005, p. 58-59).

Práxis Educativa, Ponta Grossa, v. 16, e2116594, p. 1-15, 2021

Disponível em: <https://www.revistas2.uepg.br/index.php/praxiseducativa> 
A luta organizada pela emancipação humana dá-se, então, na relação e na ação coletiva. Uma importante alternativa coletiva e contra-hegemônica feita visando essa luta engajada e coletiva, à luz de uma ecologia de saberes, é apontada por Santos (2010) por meio do cosmopolitismo subalterno, essa rede de solidariedade que se caracteriza pela diversidade em luta.

O cosmopolitismo subalterno manifesta-se através de iniciativas e movimentos que constituem a globalização contra-hegemônica. Consiste um vasto conjunto de redes, iniciativas, organizações e movimentos que lutam contra a exclusão econômica, social, política e cultural gerada pela mais recente encarnação do capitalismo global. (SANTOS, 2010, p. 51).

Essa práxis antes de ser individual é coletiva; é fruto de um encontro afetuoso e solidário de seres humanos que se entendem incompletos e inconclusos, e, mais ainda, que precisam dos saberes dos outros para construir um enfrentamento às opressões diversas (FREIRE, 2005). É da ecologia de saberes que conhecimento científico e conhecimento das vivências, das experiências reais, do ativismo dialogam em uma descolonização do pensar e do fazer, gerando um fazer/reflexão contra-hegemônico.

Faz-se necessário reconhecer que a perspectiva freiriana de assunção da luta sob a égide da dialogicidade, da opção política pelo/a oprimido/a e contra a opressão implicava, também, não apenas na escrita de um novo tempo, mas de uma nova geografia que reconhecesse o nordeste brasileiro como cenário de opressões diversas. Essa opção libertadora freiriana dava-se à luz de uma geopolítica (MOLDONADO-TORRES, 2010). É no contexto do nordeste brasileiro de pobreza extrema que se iniciaram as experiências educativas de Paulo Freire. Como Diretor do Setor de Educação e Cultura do Serviço Social da Indústria (SESI), ele teve o seu contato com a educação de Trabalhadores. Foram 15 anos de experiência acumulada na Educação de Jovens e Adultos, com trabalhadores/as tanto do campo quanto da cidade (FREIRE, 1967). Além disso, a sua participação ao longo de cinco anos nos Movimentos de Cultura Popular, no Recife, capital do estado do Pernambuco, foi fundamental para o amadurecimento de seu pensamento educativo, que já o acompanhava há longas datas, fruto de suas relações de educador com o proletariado pernambucano.

Nesse período, Freire foi Coordenador do Projeto de Educação de Adultos quando então criou os Círculos e os Centros de Cultura. Foi nos Círculos de Cultura que os debates em torno de diversas questões sociais e econômicas nacionais e locais deram pistas e provocações para a proposição daquilo que viria a ser o "Método Paulo Freire". A programação dos debates era feita pelos próprios grupos, por meio de entrevistas que Freire e sua equipe realizavam, e delas resultavam temáticas diversas sobre problemas reais que afligiam aqueles homens e aquelas mulheres com endereço e tempo definidos (FREIRE, 1967).

O debate dessas temáticas era apoiado por projeções visuais feitas por epidiascópio e de forma dialogal. Foram os resultados surpreendentes desses diálogos que provocaram em Freire a centelha de seu Método e, principalmente, do seu pensamento engajado.

Com seis meses de experiências, perguntávamos a nós mesmos se não seria possível fazer algo, com um método também ativo, que nos desse resultados iguais, na alfabetização do adulto, aos que vínhamos obtendo na análise de aspectos da realidade brasileira. Desde logo, afastáramos qualquer hipótese de uma alfabetização puramente mecânica. Desde logo, pensávamos a alfabetização do homem brasileiro, em posição de tomada de consciência, na emersão que fizera no processo de nossa realidade. (FREIRE, 1967, p. 103).

Freire (1967) relata que a primeira experiência foi realizada no Recife com a colaboração da equipe do Serviço de Extensão Cultural da Universidade do Recife com um grupo de cinco 
analfabetos da zona rural, com manifesta apatia diante dos problemas, dos quais dois desistiram, no segundo ou terceiro dia. As experiências reforçavam a convicção de Freire de que os seres humanos em processo de humanização não apenas estão no mundo, mas estão com o mundo. $\mathrm{E}$ é nas relações que estabelecem com o seu mundo que eles criam e recriam suas realidades. Além do que, nessas relações com a realidade e na realidade, o ser humano estabelece uma relação específica - de sujeito para objeto - que tem como produto o conhecimento, expresso pela linguagem.

No entanto, como lembra Thomas Kuhn (1998), as novas descobertas necessitam de novos conceitos e vocabulário específico para dar conta dos novos eventos. Assim, com a nova concepção de educação assumida, desestabiliza-se o universo conceitual habitual. Os Círculos de Cultura suplantam a noção de escola: no lugar do professor que cristaliza a noção de dono e condutor dos saberes, aparecia o coordenador de debates; no lugar das aulas expositivas, existiam diálogos; e, diferentemente de mostrar conteúdos, os Círculos de Cultura propunham Unidades de Aprendizagem; no lugar de alunos/as, alfabetizandos/as (FREIRE, 1967).

Os 15 anos de experiência acumulada na Educação de Jovens e Adultos, agindo e refletindo suas ações com um coletivo de educadores, poetas, teatrólogos, em áreas proletárias, tanto nas cidades quanto nos campos, foi o cenário que permitiu a Paulo Freire florescer, experimentar seu Método e dar vida a seu pensamento descolonial, de rompimento com as opressões nas dimensões do ser, do saber e do poder. Na constituição de seu Método, Paulo Freire não contou apenas com a equipe de professores e pesquisadores diversos da Universidade do Recife.

A contribuição do poeta e teatrólogo paraibano Ariano Suassuna foi decisiva no que tange à presença rica da arte em seu Método, pois, após presenciar atentamente a exposição do Método por Freire, Suassuna faz a crítica de que a parte plástica da proposta precisava ser melhorada, uma vez que não acompanhava a extraordinária qualidade do Método (BIOGRAFIA DE PAULO FREIRE, 2003). Com a intenção de que os alfabetizandos fizessem a leitura de mundo para depois fazerem a leitura da palavra, Freire almejava que o ser humano se descobrisse como "fazedor de cultura", capaz de criar e recriar. Nesse curso, ele descobriria que cultura é toda criação humana. Contudo, antes da conquista da linguagem, o que almejava Freire é que homens e mulheres em comunhão, ao refletirem as várias dimensões de seu mundo, vissem a si próprios/as como construtores/as de cultura e, consequentemente, como reinventadores/as de suas realidades.

Assim, além de reconhecer os princípios do Método - politicidade e dialogicacidade -, fazse necessário reconhecer outro elemento essencial: a alfabetização e a conscientização jamais se separam (e aqui é preciso alargar o significado do termo "alfabetização"). Não se educa sem a consciência de mundo e sem o reconhecimento das várias dimensões da cultura. Nos Círculos de Cultura o que importava é que homens e mulheres concretos/as, com os pés no chão e em um tempo específico, reconhecessem a si próprios/as como construtores/as de cultura. As pinturas utilizadas para introduzir os diálogos nos Círculos de Cultura expressavam a vivência, o mundo desses homens e dessas mulheres, respeitando suas próprias formas de expressão plástica.

O ato educativo era introduzido pela experiência estética dos/as alfabetizandos/as com as próprias formas de expressão plástica do mundo deles/as. Dentro de um processo de participação crítica e ativa, a partir de uma arte, experienciavam-se as várias dimensões da cultura, inclusive a arte nas suas diversas manifestações. Partia-se da pintura popular para a arte erudita, pois Freire (1967) defendia que democratizar cultura não era vulgarizar e muito menos introjetar valores culturais alheios ao povo. Almejava que a educação fosse um ato de criação que instigasse outros atos criativos. As epistemologias descoloniais também apresentam o potencial emancipatório que a arte possui e a reconhecem como uma dessas essenciais áreas com as quais se vive uma ecologia de saberes (SHOW UTÓPICO, 2016).

Práxis Educativa, Ponta Grossa, v. 16, e2116594, p. 1-15, 2021

Disponível em: <https://www.revistas2.uepg.br/index.php/praxiseducativa> 
Captar os temas próprios de cada tempo é, segundo Paulo Freire (1967), o grande desafio que se impõe aos seres humanos, sob pena de sua condição de homem/mulher ser minimizada; é na captação ou não desses temas que a humanização ou desumanização se firma. O desenho intelectual do pensamento freiriano já esboça que cada tempo consubstancia temas-problemas comuns, e, no caso específico da sociedade brasileira, vivia-se um período de transição: as velhas respostas já não davam conta de responder aos novos problemas. Embora com o pé no chão dos processos educativos, Freire acendia um candeeiro cuja chama permitia clarear caminhos bem mais largos que a Educação; transcendia-se da experiência educativa por ele proposta, para a afirmação de um modo de pensar e refletir o pensamento, uma perspectiva emancipadora que rompe a colonialidade do ser, do saber e do poder.

Firma-se, pois, em território brasileiro, um jeito novo de pensar o Brasil, em que a realidade nacional é assumida de forma autêntica, em busca de sua compreensão e transformação, cujos modelos impostados vão perdendo fôlego, dando lugar a uma consciência de ser humano, de mundo, de história e de uma educação libertadora. Nesse projeto, a educação bancária que Freire (2005) denuncia é o jeito colonial que os europeus assumiram para imprimir ao resto do mundo o "conhecimento verdadeiro" sobre os pseudoconhecimentos. Esse jeito eurocêntrico apresenta e legitima os conteúdos e as formas, os/as sábios/as e os/as ignorantes, o que deve permanecer do que deve ser descartável. Quem se educa à luz da concepção bancária/colonial e não faz o exercício árduo de desaprender não apenas o conteúdo, mas os métodos, tenderá a manter-se - mesmo quando diz assumir o contrário - do lado opressor, colonizante, considerando que:

Na visão 'bancária' da educação, o 'saber' é uma doação dos que se julgam sábios aos que julgam nada saber. Doação que se funda numa das manifestações instrumentais da ideologia da opressão - a absolutização da ignorância, que se constitui o que chamamos de alienação da ignorância, segundo a qual esta se encontra sempre no outro. (FREIRE, 2005, p. 67).

Ao pensar a experiência vivida com o fito de superar as injustiças sociais decorrentes de um sistema opressor que desumaniza seres humanos, Freire (2005) aponta outro caminho, na contramão do saber opressor, para as práticas de pensar o pensamento sobre o vivido. O lugar de onde ele fala é de educador comprometido com uma educação libertadora, e a sua educação como prática de liberdade dá uma dimensão pedagógica para uma revolução epistêmica.

Tem sido essa opção emancipadora freiriana que lastreia inúmeras epistemologias descoloniais que enfrentam a razão dominante e as opressões articuladas pelo capitalismo, o patriarcado e o colonialismo. Epistemologias que nascem do diálogo de mulheres reais que buscam solidariedade nas lutas e que não se enquadram no discurso monolítico do feminismo eurocêntrico. Trata-se de um movimento que tira da subalternidade as discussões sobre as diferenças na vida concreta das mulheres - as diferenças de raça, de sexo, de classe e de idade; epistemologias que fomentam as articulações de processos educativos emancipatórios, conjugando saberes e práticas de setores diversos, por meio do diálogo dos movimentos sociais, universidades, pastorais, grupos artísticos; epistemologias que subsidiam as ações de resistência desenvolvidas pelos movimentos sociais para a preservação de patrimônios imateriais, a exemplo de lugares sagrados para povos indígenas ou grupos de terreiro, os rituais, as danças, os artefatos, em um processo de reconhecimento da diversidade cultural tão presente nesses grupos.

A visibilidade dessas práticas possibilita uma presença, a quebra de um silêncio existencial de saberes e de experiências de grupos humanos historicamente invisibilizados. Além disso, instiga uma aproximação ao diálogo intercultural entre outras práticas, outros grupos, e, ainda, permite o questionamento às hierarquizações dos objetos, dos lugares, das pessoas e dos grupos humanos orientadas pela lógica eurocêntrica. 


\section{Ecologia Humana contra-hegemônica: uma opção latino-americana}

Diferentemente de pensar sobre os excessos urbanos, os inchaços nas cidades, que caracterizam a Ecologia Humana da Escola de Chicago, afirma-se na América Latina uma Ecologia Humana que insiste em dar protagonismo a grupos humanos subalternizados: campesinos, indígenas, quilombolas, trabalhadores e trabalhadoras sem-terra, entre outros (BONFIM, 2017). Esse protagonismo implica uma alteração de rota, uma ruptura com uma ciência que desumaniza segmentos humanos e os coloca como objeto a ser visitado e explorado. Como desdobramentos da perspectiva epistemológica adotada e, consequentemente, da concepção de ciência descolonial, os grupos humanos que se apresentam à Ecologia Humana contra-hegemônica são portadores de discursos, de saberes, de cosmologias, de geografias com quem se deseja dialogar, narrar, cartografar visando o aprendizado mútuo e a superação de questões não resolvidas pela ciência tradicional e consideradas essenciais à vida na terra. Trata-se de uma Ecologia Humana que assume o rompimento com as formas hegemônicas de pensar o pensamento dos/as outros/as, e no caso, a ruptura dá-se pelo reconhecimento de que os modelos eurocêntricos não podem mais falar por nós, brasileiros, latinos-americanos (MARQUES, 2014).

Nesse sentido, Ronaldo Alvim (2012) faz uma introdução à Ecologia Humana, situando-a tanto no seu contexto sócio-histórico, permeando seu discurso com a crítica ao projeto econômico da sociedade capitalista que gera desigualdade socioambiental e, por conseguinte, inibe quaisquer iniciativas de mudança de paradigma de vida sustentável orientada por justiça social e ambiental. Ele conceitua Ecologia Humana como a ciência das relações humanas - individuais e coletivas com o seu entorno e, portanto, responsável pela construção de novos valores e de um novo padrão de desenvolvimento que considera justiça social e valorização do espaço natural comprometido com o coletivo humano e com as várias espécies para além do Homo Sapiens. Ora, o comprometimento com o coletivo humano implica reconhecer a linha abissal que separa os doutos dos ignorantes, os civilizados dos provincianos, os desenvolvidos dos atrasados, os que têm existência própria dos inexistentes (SANTOS, 2010). O enfrentamento a que se propõe a Ecologia Humana apresentada por Alvim (2012), em que se critica o estilo de vida da modernidade, pressupõe, desse modo, o reconhecimento e o rompimento de uma geopolítica que invisibiliza povos e descarta práticas e saberes historicamente reveladores de outras formas de existência, para além daquelas reconhecidas pelo eurocentrismo.

Apesar de a Ecologia Humana centrar-se no diálogo de saberes, essa interação ainda é difícil, e o projeto societal emancipador e integralizador que se almeja ainda está distante, pois prevalece a visão fragmentada, individualista e opressora de mundo. Assim, Alvim (2012) reforça a necessidade de mudança na forma de pensar e de construir o pensamento e, por conseguinte, promover uma reconstrução social em que haja comprometimento coletivo, justiça social e ambiental, acenando para uma perspectiva descolonial que legitima não apenas a descolonialidade de poder, mas do saber e de ser (QUIJANO, 2010).

Ao fazer a interseção dos elementos constitutivos da problemática da Ecologia Humana, faz-se uma crítica radical ao projeto de desenvolvimento hegemônico, atrelando a ele a raiz do desconforto socioambiental. Ao fazer o questionamento sobre as dificuldades de alcançar sustentabilidade ambiental sem o ataque aos processos que geram má distribuição de renda, sem resistir às pressões do capital, Alvim (2012) consubstancia aquilo que Mignolo (2010) afirma: não se efetiva a desobediência civil sem a desobediência epistemológica.

A Ecologia Humana que vai sendo consolidada assume que se faz necessária uma mudança na história humana que sempre prezou o domínio da natureza. Mais do que isso, é preciso desfazer o modo de pensar eurocêntrico que se apropriou de povos e o que eles tinham de maior valor: seus corpos, suas almas, suas terras, e estabelecer um novo jeito de compreender, narrar e cartografar o

Práxis Educativa, Ponta Grossa, v. 16, e2116594, p. 1-15, 2021

Disponível em: <https://www.revistas2.uepg.br/index.php/praxiseducativa> 
mundo. Deve-se abolir a ciência da dominação e dar respostas aos problemas construídos pelo modelo capitalista dominador e opressor (FANON, 1968).

O que vem sendo provocado é uma ética ambiental fincada na autorreflexão dentro de ação coletiva. Uma ética que faça a crítica e o embate à visão superficial do desenvolvimento sustentável que não implica mudança no padrão de desenvolvimento. Ao fazer a crítica à ausência de projeto educativo engajado com uma ética comprometida com justiça social e ambiental, Alvim (2012) também faz um convite à educação libertadora que supere a intervenção ingênua e comprometase com os/as oprimidos/as, em um diálogo permanente, em que conhecimento se produz "com" e não "para". Sobre essa questão, Paulo Freire já anunciava que:

\footnotetext{
Aqueles que se comprometem autenticamente com o povo é indispensável que se revejam constantemente. Esta adesão é de tal forma radical que não permite a quem a faz comportamentos ambíguos.

Fazer essa adesão e considerar-se proprietário do saber revolucionário, que deve, desta maneira, ser doado ou imposto ao povo, é manter-se como era antes.

Dizer-se comprometido com a libertação e não ser capaz de comungar com o povo, a quem continua considerando absolutamente ignorante é um doloroso equívoco. (FREIRE, 2005, p. 54).
}

Nessa perspectiva de percepção de comprometimento ambiental que vulnerabiliza coletivos humanos, Pires e Craveiro (2011, p. 3) afirmam que a Ecologia Humana se estabelece nas inter-relações entre condições sociais e ambientais, "[...] dissecando o modo como a disponibilidade de recursos naturais e a percepção dos riscos são responsáveis por uma estratificação de populações humanas e grupos sociais". No entanto, o que precisa ser incluído nessa análise é o reconhecimento de que a apropriação dos recursos naturais está atrelada à colonialidade que se firma na consagração da superioridade de um grupo humano sobre tantos outros. Quanto mais intensa a coisificação de homens e mulheres colonizados/as, maior a usurpação de sua humanidade - de ser que se dignifica também na forma como se relaciona com a terra, também usurpada. Essa coisificação dá-se pela dominação de corpos, mentes, histórias, vínculos e lugares. Nesse sentido, Lugones (2014) destaca como os processos civilizatórios implicaram a colonização da memória e das várias dimensões da existência.

A transformação civilizatória justificava a colonização da memória e, consequentemente, das noções de si, das pessoas, da relação intersubjetiva, da sua relação com o mundo espiritual, com a terra, com o próprio tecido de sua concepção de realidade, identidade e organização social, ecológica e cosmológica. (LUGONES, 2014, p. 4).

Dessa forma, o apagamento de práticas comunitárias ecológicas e dos diferentes saberes de que os colonizados eram portadores com o fito de se instalar um jeito civilizado de ser (sempre a serviço do colonizador) repercutiu em uma avassaladora exploração da natureza e de seres bióticos e abióticos, imprimindo a concepção de que a natureza, assim como os corpos de mulheres e de homens eram territórios a serem explorados. Isso implica em um desafio posto à Ecologia Humana que se propõe contra-hegemônica: compreender a relação do ser humano com seu entorno não prescinde do entendimento ontológico de que ser humano se fala, especialmente "sobre" e "com" que ser humano se fala. O comprometimento ético de entendimento do lugar do ser humano na natureza (PIRES; CRAVEIRO, 2011) não se dissocia do compromisso com justiça social, justiça epistemológica e justiça ambiental.

Assim, atrela-se o conhecimento produzido em Ecologia Humana à superação das diversas formas de exploração/dominação dos seres vivos e seus ecossistemas. Isso implica a ruptura com as perspectivas e teorias colonizantes. Sobre isso, Paulo Freire (2003) acrescenta: 
Pensamento/ação freiriano: pistas para uma epistemologia descolonial...

O saber alicerçante da travessia na busca da diminuição da distância entre mim e a perversa realidade dos explorados é o saber fundado na ética de que nada legitima a exploração dos homens e das mulheres pelos homens mesmos ou pelas mulheres. Mas, este saber não basta. Em primeiro lugar, é preciso que ele seja permanentemente tocado e empurrado por uma calorosa paixão que o faz quase um saber arrebatado. É preciso também que a ele se somem saberes outros da realidade concreta. (FREIRE, 2003, p. 138).

Superar a perspectiva colonial que, muitas vezes, a Ecologia Humana se assentou ao atrelar as especificidades culturais e biofísicas dos povos colonizados à sua inserção geográfica, é um desafio permanente. Como destacam Pires e Craveiro:

\begin{abstract}
$\mathrm{Na}$ análise das comunidades humanas, a ecologia humana fazia ressaltar a forte associação entre as características culturais, e biofísicas dos povos e os condicionalismos específicos dos territórios que habitavam, dando lugar a um determinismo geográfico e a apreciações, muitas vezes aproveitadas para questões raciais sobre o nível de desenvolvimento das civilizações. (PIRES; CRAVEIRO, 2011, p. 5).
\end{abstract}

O determinismo geográfico e a eugenia justificaram a exploração dos seres "desumanizados" e das terras colonizadas - ventres férteis, tão fecundados pelos europeus - e, consequentemente, geraram aberrações históricas ainda em processo de assunção pela Ecologia Humana. Desse modo, muito mais do que compreender as conexões entre os sistemas sociais, econômicos e ecológicos, a ecologia humana não prescinde de compreender as pessoas a partir de seus lugares (PIRES; CRAVEIRO, 2011). Para além de pensar na igualdade entre sociosfera e biosfera, há de explicitar-se a forma de produzir conhecimento que validam práticas de produção de desigualdades no âmbito da sociosfera e como ela interfere na biosfera. Há de explicitar-se também estudos e práticas que anunciam alternativas socioambientais, a exemplo do que propõe Ostrom (2012) com os sistemas socioecológicos, em que o trabalho é realizado solidariamente, priorizando-se o monitoramento local, a confiança entre os partícipes, a interdependência, a autonomia do grupo, a formação de lideranças locais e o compartilhamento de compreensões comuns.

Muito além dos problemas ambientais decorrerem de questões relacionadas ao tempo, ao espaço e às classes sociais, têm-se um modelo de pensar que orienta diversas opressões orquestradas pelo capitalismo global; um projeto societal estabelecido e alimentado por uma ciência colonial que neutraliza todos os saberes que não são construídos sob seus pilares. Esse projeto assume a natureza como coisa a ser constantemente explorada e colocada a seu serviço.

Ao situar a Ecologia Humana como resposta às tantas crises provocadas pelas intervenções humanas sobre a natureza e sobre si mesmo, e enxergando os não lugares das dimensões subjetivas, Marques (2015) apropria-se de vários campos de conhecimento que trabalham com a noção de corpo e alma: a Psicanálise, a Antropologia, a Genética, para diminuir o fosso que ainda separa os estudos das relações do corpo com as dimensões simbólicas, culturais, bio-físico-químicas, e, nesse sentido, fortalece a Ecologia Humana como ciência da beleza e da existência que toma o corpo não como um organismo vivo, aglomerado de órgãos, mas um elemento relacional do ser com o mundo, carregado de força criativa, de beleza e de magia.

Com isso, faz-se o confronto das ecologias que propõem (MARQUES, 2012, 2015, 2016) com os ditames de um capitalismo que reifica corpo e alma e os coloca como mercadorias sob a égide de relações de dominação/exploração, não mais circunscritas na esfera do trabalho, mas nas tantas dimensões da subjetividade, colocando em xeque inclusive a natureza, o sentido e a finalidade de muito conhecimento acumulado, dentre eles o da Engenharia Genética. Um capitalismo que apaga corpo e alma, aprisionando-os, e, com isso, inviabiliza a condição do corpo de ser ponto de

Práxis Educativa, Ponta Grossa, v. 16, e2116594, p. 1-15, 2021

Disponível em: <https://www.revistas2.uepg.br/index.php/praxiseducativa> 
encontro do ambiente interno, a alma, com o macro ambiente - a natureza, a cultura, a ancestralidade, o cosmo (MARQUES, 2015). Sobre esse aprisionamento, Freire (2005) revela:

\begin{abstract}
Todo ato de conquista implica um sujeito que conquista e um objeto conquistado. $\mathrm{O}$ sujeito da conquista determina suas finalidades ao objeto conquistado, que passa, por isso mesmo, a ser algo possuído pelo conquistador. Este, por sua vez, imprime sua forma ao conquistado que, introjetando-o, se faz um ser ambíguo. Um ser como dissemos já, 'hospedeiro' do outro. Desde logo, a ação conquistadora, ao reificar os homens, é necrófila. (FREIRE, 2005, p. 157).
\end{abstract}

Na contramão dessa reificação, assume-se, para efeito deste estudo, uma Ecologia Humana com matiz latino-americana, de afastamento do chão homogeneizante de pensar, amarrar, universalizar e separar pensamento, afeto e práticas humanas concretas. Uma área de conhecimento plural que se propõe a analisar as interconexões de questões presentes nas Ciências Humanas, nas Ciências Naturais e na Psicanálise. Debruça-se, pois, em problematizar ecologias humanas, especialmente aquelas que trazem para a centralidade da análise as categorias ainda subalternizadas no campo científico, a saber: a alma, o espírito, a subjetividade humana (MARQUES, 2012, 2015, 2016).

$\mathrm{Na}$ trilogia produzida por Marques, busca-se emendar a fratura entre natureza e cultura e faz-se a crítica às classificações das coletividades, enfatizando que elas homogeneízam, formatam e encaixotam as almas humanas de maneira a enquadrá-las nos moldes colonizantes e patriarcais de uma ciência eurocêntrica. Faz-se, ainda, o contraponto de que nos povos e nas comunidades tradicionais observa-se uma fuga dessa lógica de homogeneização e invisibilização, ainda que esses grupos apresentem o maior potencial de respeito e conservação da biodiversidade.

Com isso, firma-se, no chão latino-americano, a Ecologia Humana sob a égide da dialogicidade e politicidade freirianas, um saber descolonizador que rompe com os ditames eurocêntricos que desintegraram o ser humano. Marques (2012) propõe um encontro de saberes científicos com saberes não científicos como sobrevivência planetária de seres humanos e outras espécies. Ele afirma, ainda, que se faz necessária a opção radical por uma ecologia da alma que, como uma epistemologia não apenas cognitiva mas também afetiva, longe da ilusão da ingênua ideia da natureza intocada, reintegre a dimensão simbólica do ser humano à sua dimensão biológica, entendendo-as como uma unidade indissociável e parte do mundo, em uma perspectiva que rompe a disciplinaridade, forjando uma nova ciência aberta, dinâmica, para além do eurocentrismo.

Marques (2012) faz a crítica à sociedade capitalista como violadora das dimensões simbólicas da natureza e do ser humano, a um projeto de sociedade que coloca os seres bióticos e abióticos a serviço da dominação, da exploração e do consumo exacerbado. Esse modelo de desenvolvimento econômico retirou a alma da terra, das pessoas e dos demais seres. Não se produz e se consome para responder às necessidades da vida na sua justa condição para todos e todas, mas para a riqueza de uns em detrimento de tantos.

A banalização dessas abordagens nas ciências está aliada ao reelaborado processo de dominação sobre as pessoas e sobre o mundo, pois, atinge, sobremaneira, grupos humanos culturalmente diferenciados, cujas existências remetem a este lugar dos "semalmas" para os dominadores, e de um Planeta como recurso alimentar ao voraz mundo maquínico moderno. Dessa lógica extrai-se: só é protegido e intocável quem tem alma. Se alguns sub-humanos e a Terra, não têm almas, não os decifre, devore-os. Essa lógica diz muito ao fracasso das lutas humanitárias e conservacionistas, observado ao longo da história humana. (MARQUES, 2012, p. 52).

A ecologia da alma é antes de tudo uma denúncia epistemológica para as denúncias socioecológicas, entrecruzando a crítica à injustiça cognitiva com injustiça societal. Em seu ensaio, 
Juracy Marques (2012) realiza uma crítica contundente à arrogância científica que, além de não dar conta de responder às angústias criadas pelos processos "civilizatórios", destituiu o ser humano da sua condição de parte indissociável de uma natureza complexa. Sem a pretensão de incluir a discussão da ecologia da alma nos auspícios científicos, robustece uma nova perspectiva epistemológica que não apenas faz a crítica à ciência eurocêntrica, mas aponta caminhos para a necessária revisão interna da ciência que não mais pode ser pensada senão em sua pluralidade interna e em uma permanente ecologia de saberes em que o científico e não científico dialogam com muita afetividade (SANTOS, 2010).

Essa ecologia contra-hegemônica apresentada nos constructos de Alvim (2012), Pires e Craveiro (2011) e Marques (2012, 2014, 2015, 2016) desafia e desestabiliza os pilares da ciência eurocêntrica ao aclamar não apenas novas abordagens, mas novas temáticas, novos lugares, novos discursos, especialmente por incluir um novo ser que assumiu a humanidade proscrita. Trata-se de uma perspectiva que insere o pensamento na dimensão cósmica para além do definido pelos contornos científicos, dando visibilidade à defesa dos patrimônios imateriais dos povos indígenas e, com isso, acena para a consolidação desse espaço, em que o espiritual, que é natural, é protegido (ou acena por proteção) por políticas públicas (MARQUES, 2016).

A criação de sociedades, organizações sociais, projetos compostos por pesquisadores de diferentes áreas de conhecimento, ativistas sociais, representantes de comunidades e povos tradicionais para dar visibilidade às narrativas desses coletivos, traduzindo lutas por inclusão de invisibilidades e negação históricas em direitos, em justiça social e epistêmica, como se observa no Projeto Nova Cartografia Social da Amazônia, entre tantos movimentos similares que agregam a pluriversidade cognitiva e ecologia de saberes, tem sido um fundante exercício descolonial. Esse exercício de descolonizar corpos e mentes exige resistência civil e epistêmica, advindos de enfrentamentos plurais, lastreado pela lição freiriana de expulsar o hospedeiro opressor, a partir de uma educação libertadora.

São inúmeras vozes insurgentes, novas histórias, novas geografias, uma geopolítica que robustece a crítica ao etnocentrismo, a partir desse conjunto de movimento epistemológico descolonial plural que tem em comum o horizonte de justiça socioambiental e cognitiva. Assim, vai se afirmando, em solo brasileiro, uma ecologia humana que dá centralidade às relações que os coletivos humanos tradicionais estabelecem com a natureza, especialmente os povos indígenas (ALMEIDA, 2014); um conhecimento acadêmico que se estabelece a partir de jeitos novos e dissidentes de se produzir saberes. Nesse caminho, a clareza do engajamento científico a serviço de grupos humanos historicamente invisibilizados, aliado a metodologias colaborativas (BIDASECA, 2018), permite a constituição não apenas de um novo protagonismo discursivo, mas também de uma nova cartografia e de uma nova concepção de ser. A forma como essas comunidades concebem e lidam com o ecossistema, especialmente o lugar sagrado que a natureza assume para elas, não se dissocia do conhecimento que se produz à luz da ecologia de saberes proposta por Santos (2010) como alternativa epistemológica e social.

\section{Considerações finais}

No eixo estruturador do pensamento de Paulo Freire está o rompimento com o sistema opressor por meio de processos emancipatórios que, ao enfrentar a educação opressora, enfrenta concomitantemente a superação da opressão que se hospeda no ser humano e que lastreia relações de poder opressoras. Esse rompimento com a tríade opressora do saber, do ser e do poder, explicitado pela ruptura com o protagonismo discursivo eurocêntrico, caracteriza as perspectivas descoloniais que se afirmam no sul metafórico, dentre elas a ecologia humana contra-hegemônica. 
A práxis freiriana que interconecta relações de poder nas relações do saber (politicidade), fomentando, nesse processo, a afirmação do ser humano, que, em permanente comunhão com outros seres, vai se humanizando (dialogicidade), transcende a contribuição epistemológica de Paulo Freire para além da teoria da educação, cimentando, assim, uma epistemologia, um modo de orientar a produção do conhecimento em várias áreas do conhecimento. A dialogicidade freiriana instiga a ecologia de saberes que notadamente orienta as teorias descoloniais, que não apenas reconhecem a pluralidade da ciência, como entendem que as práticas emancipatórias não prescindem do diálogo da ciência com outros saberes, dentre eles a ancestralidade e as artes.

O aceite ao convite freiriano de enfrentamento ao sistema opressor - caracterizado pelos processos de dominação/exploração articulado pelo capitalismo com o colonialismo e o patriarcado -, por meio do encontro engajado de seres humanos que aprendem na comunhão de suas diferenças, a partir do entendimento de que a desumanização/exploração a que foram sucumbidos, é decorrente de um saber opressor que neles habita, é o lastro em que se assentam a descolonialidade e o horizonte de justiça socioambiental e cognitiva.

Se, por um lado, afirma-se um vínculo seminal do pensamento/ação freiriano com as epistemologias descoloniais; por outro, tem-se ambas as discussões dando sustentação a uma ecologia humana contra-hegemônica que vem se firmando na América Latina. Uma ecologia humana das subjetividades, dos movimentos sociais que não apenas foram forjados sob os ideais freirianos de superação de opressões vividas, mas que têm mostrado que as cartografias por eles construídas têm novos contornos que tanto dão visibilidade às opressões como a seus enfrentamentos.

Essas identidades coletivas que povoam os diversos territórios brasileiros têm na terra seu mais caro valor, porque a entendem como extensão indissociável de suas existências. Isso implica uma ruptura com o jeito eurocêntrico de representar os lugares, o tempo, os seres humanos e a própria noção de evolução. Essa Ecologia Humana reconhece que o protagonismo desse ser coletivo e historicamente inexistente - na lógica do pensamento abissal - é vital para que se atribua à natureza uma nova representação, bem distante do velho ideal mercadológico. Essa Ecologia Humana de sangue latino-americano estabelece-se do diálogo não apenas interno com outras ciências, mas com o coletivo de pescadores, ribeirinhos, quilombolas, indígenas, povos da floresta, entre outros; a Ecologia Humana dos invisíveis, em busca da sociobiodiversidade como sobrevivência para a terra e seus elementos constitutivos.

O pensador brasileiro que nos brindou com Educaşão como prática de liberdade e Pedagogia do oprimido não apenas se insere na genealogia das epistemologias e teorias descoloniais, mas com elas segue no permanente enfrentamento a todas as formas de opressão. E, com a Ecologia Humana, ele afirma um encontro afetivo do ser humano consigo e deste com as diferentes formas de ser e de estar no mundo, em que biosfera e sociosfera são dois lados de um todo complexo e indivisível que a colonialidade violentamente atacou.

\section{Referências}

ALMEIDA, A. W. B de. Ecologia dos povos e comunidades tradicionais do Brasil. In: MARQUES, J. (org.). Ecologias humanas. Feira de Santana: UEFS, 2014. p. 43-52.

ALVIM, R. Ecologia humana: da visão acadêmica aos temas atuais. Maceió: EDUFAL, 2012. 
BARBOSA, V. L. E. Modernidade, descolonialidade e educação popular: perspectivas da pedagogia da esperança de Paulo Freire. Revista Ibero-Americana de Estudos em Educação, Araraquara, v. 11, n. 1, p. 81-94, jan./mar. 2016. DOI: https://doi.org/10.21723/riaee.2016.v11.n1.p81

BIDASECA, K. La revolución será feminista o no será. La piel del arte feminista. Buenos Aires: Prometeo, 2018.

BIOGRAFIA DE PAULO FREIRE. Direção: Moacir de Oliveira. Produtor Executivo: Mário Lúcio Brandão Filho. São Paulo: Trade Comunicação, 2003. 1 vídeo (24 min, 49 s). Disponível em: https://www.youtube.com/watch?v=jzUgb75GgpE. Acesso em 20 jan. 2015.

BONFIM, L. As raízes da ecologia humana no Brasil. In: MARQUES, J.; ALVIM, R. (org.). As raízes da ecologia humana. Paulo Afonso: SABEH, 2017. p. 100-153.

FANON, F. Os condenados da terra. Rio de Janeiro: Civilização Brasileira, 1968.

FREIRE, P. Educação como prática de liberdade. Rio de Janeiro: Paz e Terra, 1967.

FREIRE, P. Pedagogia do oprimido. 46. ed. Rio de Janeiro: Paz e Terra, 2005.

FREIRE, P. Pedagogia da autonomia. 28. ed. São Paulo: Paz e Terra, 2003.

KUHN, T. S. A estrutura das revoluções científicas. 5. ed. São Paulo: Perspectiva, 1998.

LUGONES, M. Rumo a um feminismo descolonial. Revista Estudos Feministas, Florianópolis, v. 22, n. 3, p. 935-952, set./dez. 2014. DOI: https://doi.org/10.1590/s0104-026x2014000300013

MARQUES, J. Ecologia da alma. Petrolina: Franciscana, 2012.

MARQUES, J. (org.). Ecologias humanas. Feira de Santana: UEFS, 2014.

MARQUES, J. Ecologia do corpo. Paulo Afonso: SABEH, 2015.

MARQUES, J. Ecologia do espírito. Paulo Afonso: SABEH, 2016.

MENESES, M. P. Os sentidos da descolonização: uma análise a partir de Moçambique. Revista OPSIS, Catalão, v. 16, n. 1, jan./jun. 2016. DOI: https://doi.org/10.5216/o.v16i1.36904

MIGNOLO, W. Historias locales/diseños globales: colonialidad, conocimientos subalternos y pensamiento fronterizo. Madrid: Akal, 2003.

MIGNOLO, W. Desobediencia epistémica: retórica de la modernidad, lógica de la colonialidad y gramática de la descolonialidad. Buenos Aires: Ediciones del signo, 2010.

MOLDONADO-TORRES, N. A topologia do ser e a geopolítica do conhecimento. Modernidade, império e colonialidade. In: SANTOS, B. de S.; MENESES, M. P. (org.). Epistemologias do Sul. São Paulo: Cortez, 2010. p. 396-443.

MORAES, M. C. Ecologia dos saberes: complexidade, transdisciplinaridade e educação. São Paulo: Antakarana/PróLibera, 2008.

MORAES, M. C. Transdisciplinaridade e Educação. Rizoma Freiriano, Xàtiva, v. 6, p. 1-18, 2010. Disponível em: http://www.rizoma-freireano.org/transdisciplinaridade-e-educacao--mariacandida-moraes. Acesso em: 11 fev. 2021. 
MOTA, C. G. Ideologia da cultura brasileira. São Paulo: Ática, 1994.

MOTA NETO, J. C. Paulo Freire e Orlando Fals Borda na genealogia da Pedagogia decolonial latino-americana. In: REUNIÃO NACIONAL DA ANPED, 38., 2010, São Luís. Anais [...]. São Luís: Universidade Federal do Maranhão, 2017. p. 1-17.

OSTROM, E. et. al. The future of the commons: beyond market failure and government regulation. Indiana: Institute of Economic Affairs, 2012.

PENNA, C. Paulo Freire no pensamento decolonial: um olhar pedagógico sobre a teoria póscolonial latinoamericana. Revista Estudos e Pesquisa sobre as Américas, Brasília, v. 8, n. 2, p. 181-199, 2014. DOI: https://doi.org/10.21057/repam.v8i2.12609

PIRES, I. M.; CRAVEIRO, J. L. Ética e prática da ecologia humana: questões introdutórias sobre ecologia humana e a emergência dos riscos ambientais. Lisboa: Apenas Livros Ltda. e Autores, 2011. (Coleção Ecologia Humana).

QUIJANO, A. Colonialidade do poder e classificação social. In: SANTOS, B. de S.; MENESES, M. P. (org.). Epistemologias do sul. São Paulo: Cortez, 2010. p. 84-130.

SANTOS, B. de S. Para além do pensamento abissal: das linhas globais a uma ecologia de saberes. In: SANTOS, B. de S.; MENESES, M. P. (org.). Epistemologias do sul. São Paulo: Cortez, 2010. p. 31-83.

SANTOS, B. de S.; MENESES, M. P. (org.). Epistemologias do sul. São Paulo: Cortez, 2010.

SHOW UTÓPICO - Documentário. Realização: Pedro Neves. Coimbra, Porto: Centro de Estudos Sociais, Projecto Alice, Red Desert Films, 2016. 1 vídeo (34 min, 44 s). Disponível em: https://www.youtube.com/watch?v=-qy9xGltpSw. Acesso em: 10 set. 2017.

Recebido em 09/08/2020

Versão corrigida recebida em 08/02/2021

Aceito em 10/02/2021

Publicado online em 16/02/2021

Práxis Educativa, Ponta Grossa, v. 16, e2116594, p. 1-15, 2021

Disponível em: <https://www.revistas2.uepg.br/index.php/praxiseducativa> 